\title{
Routine Episiotomy Practice at a Tertiary Care Center in Saudi Arabia
}

\author{
Ayman Oraif \\ Department of Obstetrics \& Gynecology, Faculty of Medicine, King Abdulaziz University, Jeddah, Saudi Arabia \\ Email: ayman_oraif@yahoo.com
}

How to cite this paper: Oraif, A. (2016) Routine Episiotomy Practice at a Tertiary Care Center in Saudi Arabia. Open Journa of Obstetrics and Gynecology, 6, 794-797. http://dx.doi.org/10.4236/ojog.2016.613097

Received: September 11, 2016

Accepted: December 3, 2016

Published: December 6, 2016

Copyright () 2016 by author and Scientific Research Publishing Inc. This work is licensed under the Creative Commons Attribution International License (CC BY 4.0).

http://creativecommons.org/licenses/by/4.0/

(c) (i) Open Access

\begin{abstract}
Background: Episiotomy is a common perineum incision preformed to facilitate the delivery. Although it was commonly performed especially in primigravida women, the new trend is to limit episiotomies as much as possible. This study aimed to find out the rate of episiotomy and to compare the rate in primigravida vs multigravida at King Abdulaziz university hospital. Methods: A retrospective chart review was performed at King Abdulaziz University Hospital, Jeddah from January 2012 to December 2015. Ethical approval was obtained. Results: 35\% of the females in 2012 had episiotomy while the majority of the vaginal deliveries had no intervention (65\%). In 2015 , the rate of episiotomies has increased to $36.4 \%$. However, the majority of the vaginal deliveries had no intervention (63.6\%). Overall $87.6 \%$ primigravidas had episiotomy while only $12.4 \%$ delivered without intervention. On the other hand, only $16.1 \%$ multigravidas had episiotomy, while the largest portion of cases was delivered without intervention (83.9\%). Conclusion: Rate of episiotomy has slightly increased in 2015 in comparison to 2012. To decrease the overall episiotomy rate, we have to review KAUH guidelines and evaluate the limitation of applying it in practice.
\end{abstract}

\section{Keywords}

Episitomy, Routine, Saudi Arabia, Standard Practice

\section{Introduction}

Episiotomy is a common surgical incision preformed on the stretched female perineum. It can be either median or medio-lateral and it is used to increase the diameter of the outlet in order to facilitate the delivery [1].

Previously, it was recommended for all primigravida women during delivery, it was assumed that a clean surgical cut would heal faster than irregular perineal tears produced by normal delivery [1]. 
It was later noticed that episiotomies were associated with a higher rate of blood loss, infections, increased perineal pain, and some other complications [1] [2]. Although the new recommendations published by the American College of Obstetricians and Gynecologists in 2013 [3] are against using episiotomies on routine basis, many are still preformed.

A study conducted in 2014 in Buraidah, Saudi Arabia, at the mother and child hospital to study the rates of episiotomy showed an overall episiotomy rate of $51.20 \%$ more commonly performed on primigravida [4], a similar one was conducted in Oman 2015 and showed a rate of $66 \%$ primigravida episiotomies [5]. But still, there is very little information about how many episiotomies are still preformed in Jeddah, so we aimed here to study the rate of episiotomies preformed in King Abdulaziz University Hospital (KAUH) before and after the new guidelines, and to compare between primigravida and multigravida rates.

\section{Methodology}

This retrospective study was conducted at King Abdulaziz University Hospital and has been approved by the ethical committee.

The sample size was 1000 females, 500 in each year as we used a simple randomized sampling from each quarter in the years 2012 and 2015. Our target sample was all females who underwent Spontaneous vaginal delivery. The study excluded all females who underwent cesarean section.

All data has been processed through SPSS. Qualitative variables were submitted as frequencies and percentages of episiotomy in both years. We compared between rates of both years and observed the correlation between the rate of episiotomy and gravidity using chi-square test.

\section{Results}

In this study, we aimed to see the difference in the episiotomy rate before and after the guidelines release. This study was applied on 1000 females who have been delivered vaginally in 2012 and 2015.

Table 1 shows 175 (35\%) of the females in 2012 had episiotomy while the majority of the vaginal deliveries had no intervention 325 (65\%). In 2015, the number of episiotomies has increased to $182(36.4 \%)$. However, the majority of the vaginal deliveries had no intervention 318 (63.6\%).

Table 2 shows 357 episiotomies were done in 2012 and 2015. 240 (87.6\%) primigravidas had episiotomy while $34(12.4 \%)$ were delivered without intervention. On the other hand only 117 (16.1\%) out of 726 multigravidas had episiotomy, while the largest portion of cases was delivered without intervention $609(83.9 \%)(\mathrm{P}<0.001)$.

\section{Discussion}

In this study, we aimed to see the difference in the episiotomy rate before and after the guidelines release. 
Table 1. Overall episiotomy rates.

\begin{tabular}{ccc}
\hline 2012 & Frequency & Percent \\
\hline No intervention & 325 & 65.0 \\
Episiotomy & 175 & 35.0 \\
Total & 500 & 100.0 \\
2015 & & \\
No intervention & 318 & 63.6 \\
Episiotomy & 182 & 36.4 \\
Total & 500 & 100.0 \\
\hline
\end{tabular}

Table 2. Episiotomy rate in primigravida compared to multigravida.

\begin{tabular}{ccccc}
\hline & & \multicolumn{2}{c}{ Episiotomy } & Total \\
\cline { 3 - 4 } & & No & Yes & \\
\hline \multirow{2}{*}{ Primigravida } & Count & 34 & 240 & 274 \\
& \% within gravidity & $12.4 \%$ & $87.6 \%$ & $100.0 \%$ \\
Multigravida & Count & 609 & 117 & 726 \\
& \% within gravidity & $83.9 \%$ & $16.1 \%$ & $100.0 \%$ \\
& Count & 643 & 357 & 1000 \\
& \% within gravidity & $64.3 \%$ & $35.7 \%$ & $100.0 \%$ \\
\hline
\end{tabular}

We found that the rate of episiotomy in 2015 was $36.4 \%$, so we are still behind on following the new guidelines [3] in comparison to France who reported a rate of $13.3 \%$ in 2009 [6] and England 20\% [7], Sweden reported a rate of 30\% episiotomy [8] which is somewhat close to our rate. However we are ahead of Argentina who reported an Episiotomy rate of $83 \%$ [9] and Kaufman from USA who reported 50\% [10]. WHO has conducted a review that showed that episiotomy has failed to decrease the rates of perineal tears [11]. Also, the American College of Obstetricians and Gynecologists (ACOG) practice bulletin shows that the median episiotomy has high rates of injury to the anal sphincter and rectum, and their guidelines recommend to restrict use of episiotomy in clinical practice [3]. The Journal of the American Medical Association (JAMA) review show that episiotomy cause more pain and more lacerations than no episiotomy [12].

In 2012 (before the guidelines), the rate was 35\%. Unfortunately, in 2015 (after the guidelines) the rate was increased to $36.4 \%$ instead of being decreased. Failure to decrease the rate could be due to different circumstances between the groups, which could've contained more patients with indications of episiotomy, or it could be that the doctors or patients actually prefer to preform episiotomies.

When the rate of episiotomy between primigravida and multigravida were compared, the study showed that primigravida has a higher rate (87.6\%) because of rigid perineum and instrumental delivery [4], while the rate in multigravida was (16.1\%). 


\section{Conclusion}

Rate of episiotomy has slightly increased in 2015 in comparison to 2012. We recommend lowering the rates as much as possible without increasing the perineal injuries by raising awareness of possible complications of episiotomy and that episiotomy is not the primary method of delivering a baby, also to encourage practitioners to limit episiotomy use in accordance with the guidelines.

\section{Acknowledgements}

Special thanks to Ammar Alfatni, Abdulhadi Alama, Abdulrahman Hawari, Yazeed Al Subhi, Hisham Alghanmi in collecting and processing the data.

\section{References}

[1] Thacker, S.B. and Banta, H.D. (1983) Benefits and Risks of Episiotomy: An Interpretative Review of the English Language Literature, 1860-1980. Obstetrical \& Gynecological Survey, 38, 322-338.

[2] Larsson, P.G., Platz-Christensen, J.J., Bergman, B. and Wallstersson, G. (1991) Advantage or Disadvantage of Episiotomy Compared with Spontaneous Perineal Laceration. Gynecologic and Obstetric Investigation, 31, 213-216. http://dx.doi.org/10.1159/000293161

[3] ACOG (2006) Episiotomy (Practice Bulletin \#71). Obstetrics \& Gynecology, 107, 957-962.

[4] Saadia, Z. (2014) Rates and Indicators for Episiotomy in Modern Obstetrics-A Study from Saudi Arabia. Mater Sociomed, 26, 188-190.

[5] Al-Ghammari, K., Al-Riyami, Z., Al-Moqbali, M., Al-Marjabi, F., Al-Mahrouqi, B., AlKhatri, A. and Al-Khasawneh, E.M. (2016) Predictors of Routine Episiotomy in Primigravida Women in Oman. Applied Nursing Research, 29, 131-135.

[6] Reinbold, D., Eboue, C., Morello, R., Lamendour, N., Herlicoviez, M. and Dreyfus, M. (2012) From the Impact of French Guidelines to Reduce Episiotomy's Rate. Journal de Gynécologie Obstétrique et Biologie de la Reproduction (Paris), 41, 62-68. http://dx.doi.org/10.1016/j.jgyn.2011.08.006

[7] London: Department of Health (1997) Department of Health, NHS Maternity Statistics, England 1989-90 to 1994-5.

[8] Rockner, G. and Olund, A. (1991) The Use of Episiotomy in Primiparas in Sweden. A Descriptive Study with Particular Focus on Two Hospitals. Acta Obstetricia et Gynecologica Scandinavica, 70, 325-330. http://dx.doi.org/10.3109/00016349109007881

[9] Argentine Episiotomy Trial Collaborative Group. Routine vs Selective Episiotomy: A Randomised Controlled Trial. Lancet, 1517-1518.

[10] Kaufman, S.C. (1992) Episiotomy. To Cut or Not to Cut? Online J Curr Clin Trials Doc, 16.

[11] Liljestrand, J. Episiotomy for Vaginal Birth: RHL Commentary (2003) The WHO Reproductive Health Library. World Health Organization, Geneva.

[12] Hartmann, K., Viswanathan, M., Palmieri, R., Gartlehner, G., Thorp, J. and Lohr, K.N. (2005) Outcomes of Routine Episiotomy: A Systematic Review. JAMA, 293, 2141-2148. http://dx.doi.org/10.1001/jama.293.17.2141 
Submit or recommend next manuscript to SCIRP and we will provide best service for you:

Accepting pre-submission inquiries through Email, Facebook, LinkedIn, Twitter, etc. A wide selection of journals (inclusive of 9 subjects, more than 200 journals)

Providing 24-hour high-quality service

User-friendly online submission system

Fair and swift peer-review system

Efficient typesetting and proofreading procedure

Display of the result of downloads and visits, as well as the number of cited articles

Maximum dissemination of your research work

Submit your manuscript at: http://papersubmission.scirp.org/

Or contact ojog@scirp.org 